\title{
Information Content of CSI 300 Index Futures during Extended Trading Hours: Evidence from China
}

\author{
Yugang Chen \\ Associate Professor of Finance, Business School \\ Sun Yat-sen University \\ 135 Xingang Road, Guangzhou, China, 510275 \\ E-mail: chenyugang76@163.com
}

\author{
Karen Jingrong Lin (Corresponding author) \\ Assistant Professor of Accounting, Manning School of Business \\ University of Massachusetts-Lowell / Sun Yat-Sen University \\ 1 University Avenue, Lowell, MA, 01854 \\ E-mail: Jingrong_lin@uml.edu
}

Received: March 10, 2013 Accepted: April 9, $2013 \quad$ Published: June 1, 2013

doi:10.5296/ajfa.v5i1.3365 URL: http://dx.doi.org/10.5296/ajfa.v5i1.3365

\begin{abstract}
China established its stock futures exchange in year 2006, but not until year 2010 did the first futures contract become publicly available for trading. The tight government as well as the composition of market participants raises the question that whether this futures market is informationally efficient. We study the information incorporation of the futures market during the extended trading hours beyond those of the underlying spot market. Our analyses show that, first, spot market is the main information source of the futures market. In addition, using a T-GARCH model, we show that the post-closing, overnight and pre-opening returns are significantly correlated with the overnight spot market return. Second, the return innovations of the futures market significantly correlate with the overnight spot market return, indicating a price discovery role of the futures market. Finally, the futures market during the extended hours reflects the overnight news in the U.S. market.
\end{abstract}

Keywords: Stock Index Futures, Information Content, Price Discovery, Extended Trading Hours 


\section{Introduction}

We investigate information efficiency of the futures market in an important emerging economy, China. In particular, we explore whether the CSI 300 Index futures traded during extended trading hours (i.e., after the spot equity market is closed or before it is open) incorporate additional information. Following other markets around the world, China has adopted asynchronous opening and closing times between the spot and the futures market. We investigate the information role of the futures market by examining information incorporation of the CSI 300 index futures during the non-trading hours of the underlying spot market.

The capital market in China is heavily regulated with numerous unsophisticated individual traders as market participants ${ }^{1}$. Thus, the equity market in China is often considered to be weakly efficient regarding information incorporation (Chong, Lam, \& Yan, 2012; Gul, Kim, \& Qiu, 2010; Morck, Yeung, \& Yu, 2000). In 2006, the Chinese Securities Regulatory Commission (CSRC) established the China Financial Futures Exchange (FFEX), but it was not until year 2010 that the first futures product based on the equity market index, the CSI 300 index, was publicly available for trading. The government was cautious about the risks involved in developing the financial derivatives markets in China, and investors are concerned about the market efficiency of these markets. Under tight control by the government, it is unclear whether China's futures market is informationally efficient.

In this study we address three interrelated research questions. First, how are returns from different trading sessions of futures during the non-trading hours related to the overnight spot market return? Second, following Hiraki, Maberly, and Takezawa (1995) and Cheng, Jiang, and $\mathrm{Ng}$ (2004), does the return innovation extracted from the futures market during the extended trading hours explain the overnight spot return? Finally, is the overnight futures market effective in incorporating information from the main overseas markets such as the U.S. market? In particular, we investigate two sources of additional information: the price volatility in the U.S. market, as well as the overnight news of the U.S. market (such as interest rate news released by the Federal Reserve).

Using high-frequency trading data at the minute level during April 16, 2010 to February 28, 2011, we were able to divide the trading of futures during extended hours into three parts: post-closing trading session (15:00-15:15pm), overnight session (15:15-9:15, next day), and pre-opening trading session (9:15-9:30). Our analyses generate empirical evidence as follows. First, we confirm that the underlying spot equity market is the main information source of the futures market. Specifically, trading of futures contracts during a post-closing session is less active and conveys less information than it does when the spot market opens. In addition, the three trading sessions of CSI 300 index futures are significantly correlated with the overnight spot CSI 300 index return. Second, we find significant explanatory power of the futures return innovations of the post-closing and pre-opening sessions on overnight spot returns. This suggests that post-closing and pre-opening sessions convey private information about

\footnotetext{
${ }^{1}$ Individual investors are the major force of the stock market. For example, in 2009 the aggregate value of stocks possessed by institutional investors increased to 54.62 percent. http://www.china.org.cn/business/news/2009-05/06/content_17732363.htm
} 
the overnight spot market. Finally, we confirm the overnight return of the futures market incorporates information from a major overseas market, in our case, the U.S. market. This result is consistent with the contagion model presented by King and Wadhwani (1990).

Our study contributes to the existing literature in the following ways. First, we provide evidence of information efficiency of the newly incepted futures market in China, adding to the existing knowledge about futures markets in emerging economies such as Hong Kong and Korea (Cheng et al., 2004; Chong et al., 2012; Min \& Najand, 1999). Second, our study sheds light on the information transfer between China's spot and futures market, as well as that between China's market and the U.S. market.

The rest of this study is organized as follows: Section 2 is a literature review and hypotheses development, section 3 introduces data and methodology, section 4 discusses empirical results, and section 5 concludes.

\section{Literature Review and Hypothesis Development}

Information content as well as information efficiency of futures market has attracted enormous academic attentions because prices of futures are usually used as measures of market expectations. An informationally efficient futures market should deliver futures prices that accurately predict prices of the spot markets in the future (e.g., Bigman, Goldfarb, \& Schechtman, 1983). Based on this understanding, a voluminous literature documents the correlation between the volatility of the futures and spot market (e.g., Antoniou \& Holmes, 1995; Chang, Cheng, \& Pinegar, 1999).

However, it has been not explored that whether the newly-launched China's futures market is informationally efficient or not. On the one hand, the highly-regulated Chinese markets can generate fluctuate stock prices conditional on political swings on both the spot (Morck et al., 2000) and futures markets, reducing the predictability of the futures prices to the future spot prices. The fact that the major participants of the futures markets are unsophisticated investors exacerbate the problem of futures market may lack information efficiency. On the other hand, the long-time deliberation and preparation of the Finance Ministry and the stringent administrative environment indicate that this market is on the attention of high-level government attentions. Therefore, if informationally inefficient, the government will interfere and change the regulatory environment.

We test the information efficiency of the futures market in China by asking the following research question: how are returns from different trading sessions of futures during the non-trading hours related to the overnight spot market return? Hiraki et al. (1995) show that the closing returns of the previous day and the opening returns on the next day are positively correlated, indicating information across different dates transmission during trading (e.g., Kyle, 1985). Following this spirit, if the spot market is a good source of information for the futures market, we should observe that the post-closing, overnight and pre-closing returns of the futures market are positively correlated with the overnight spot return. We therefore form our hypothesis (written in the null form) as follows:

H1a. The post-closing, overnight and pre-opening returns of the futures market are not 
correlated with the overnight spot return.

If CSI 300 index futures convey additional information to the spot market, the 15-minute extended trading session after the spot market closes allows investors to continuously incorporate information. Similarly, trading activities in the futures market during the 15-minute pre-opening session impound overnight information before the spot market opens. That is, the unexpected returns in the futures market during these two trading sessions shall be able to predict the overnight spot market returns.

Both Foster and Viswanathan (1994) and Hiraki et al. (1995) find that informed traders strategically trade on their private information and trading of futures contracts during post-closing and pre-opening sessions reveals informed traders' private information and facilitates price discovery of the spot market. However, in a country where political control is overwhelming, information arbitrageurs will be driven away thus stock prices reflects only public and common information (Morck et al., 2000). China is one of such country according to Morck et al. (2000). Therefore, a priori, it is difficult to predict whether China's index futures market incorporates information additional to that traded in the spot market. We use a T-GARCH (1,1) model (Engle \& Ng, 1993; Zakoian, 1994) to extract the returns innovation from the extended trading hours to predict the overnight spot market returns ${ }^{2}$. The second hypothesis (written in the null form) is formulated as the following:

H1b. The return innovations of CSI 300 index futures contracts during the extended trading hours do not correlate with the overnight spot return of the CSI 300 index.

One important information source for the futures market after the spot market closes will be information from the overseas market. King and Wadhwani (1990) find that rational investors infer private information from trading in other markets. Lin, Engle, and Ito (1994) find that the Tokyo and New York stock exchanges have correlated overnight and daytime returns, indicating information revealed during the trading hours of one market has a global impact on the returns of the other market. Following these arguments, we examine whether overnight CSI300 index futures returns incorporate news from the daytime trading in the U.S. market, and our third hypothesis (written in the null form) is the following:

H2. The trading of futures contracts does not reflect the overnight information arrival in the U.S. market.

\section{Data and methodology}

\subsection{Extended Trading Hours of the Spot Market}

We obtained the high-frequency trading data at the minute level from the Tinysoft database. We divide each day's trading into fifteen-minute intervals. The normal trading hours of the spot market is 9:00-15:00 every day. The extended trading hours of futures contracts are

\footnotetext{
2 Engle and $\mathrm{Ng}$ (1993) show that, in Japan's market, the T-GARCH model is the best parametric model when there is asymmetric return volatility conditional on news types. (Chiang \& Wang, 2002) used it to investigate the Taiwan futures market. We therefore follow this approach because we assume that Asian countries share commonalities in market microstructures.
} 
9:15-9:30am and 15:00-15:15 (3:00-3:15pm). We further decompose the return of CSI 300 futures in the non-trading hours of the spot market as the following:

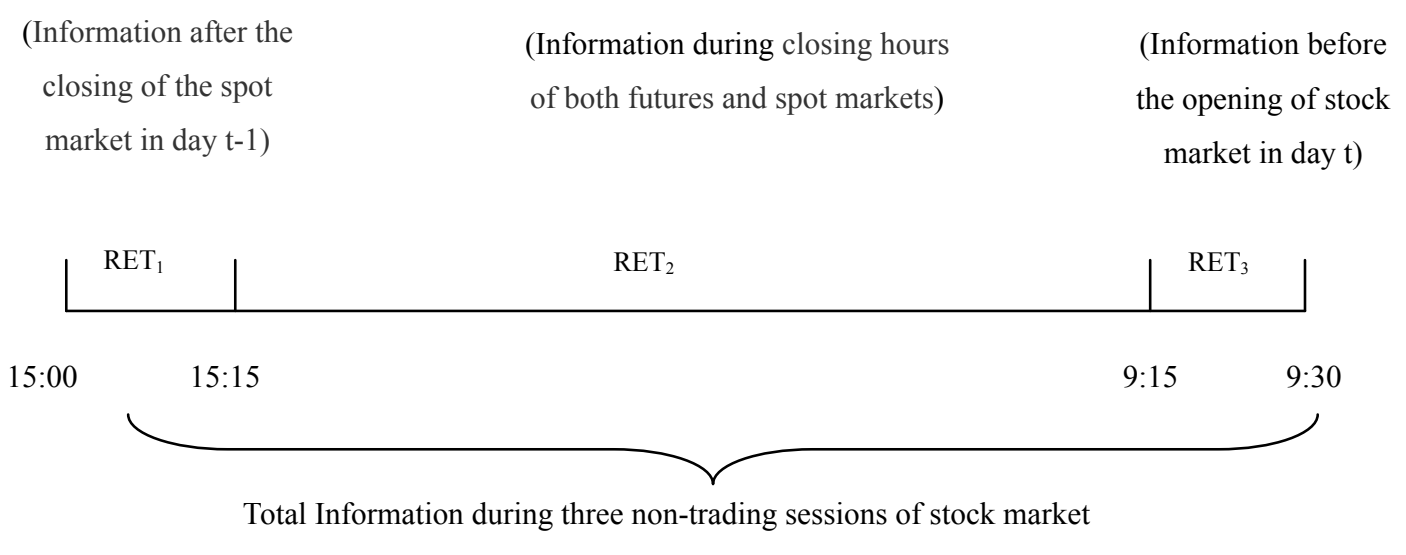

$\left(\mathrm{RET}_{300}\right)$

\subsection{Information Captured By the Futures and Spot Markets}

To test hypotheses H1a, we test the difference of the price change, return and trading volume of the CSI 300 index futures during the three sessions: pre-opening of the spot market, opening of the spot market, and post-closing of the spot market. This test is more descriptive in nature.

To test $\mathrm{H} 1 \mathrm{~b}$, we run the following regression model, Eq (1), in which spot market overnight return of day $\mathrm{t}$ (i.e., $\mathrm{RET}_{300, \mathrm{t}}$ ) is regressed on the futures return during three sessions: post-closing return of day $\mathrm{t}$ (i.e., $\mathrm{RET}_{1, \mathrm{t}}$ ), overnight return (i.e., $\mathrm{RET}_{2, \mathrm{t}}$ ), and pre-opening return of day $\mathrm{t}+1$ (i.e., $\mathrm{RET}_{3, \mathrm{t}}$ ). We labeled all three sessions with subscript $t$ to reflect the fact that these returns are regressed corresponding to the overnight spot market return of a particular day.

$$
R E T_{300, t}=\alpha_{i}+\beta_{1} R E T_{1, t}+\beta_{2} R E T_{2, t}+\beta_{3} R E T_{3, t}+\epsilon_{t},
$$

and $R E T_{300, t}$ is calculated as follows:

$$
R E T_{300, t}=\frac{P_{t}-P_{t-1}}{P_{t-1}}
$$

where $P_{t}$ is the opening price of CSI 300 in day $t$, and $P_{t-1}$ is the closing price of day $t-1$.

Empirically, we use the T-GARCH model (Zakoian, 1994) to estimate the coefficients. Statistically significant coefficients $\beta_{1}, \beta_{2}$, or $\beta_{3}$ imply that (at least partially) the futures market captures information that is incorporated into the spot market. The underlying information between the two markets is similar.

\section{Additional Information Reflected in the Futures Market}

To test H2, we follow Hiraki et al. (1995) and Cheng et al. (2004), using a two stage model to extract information from the futures returns and to predict the overnight spot market return. In the first stage, a T-GARCH $(1,1)$ model is used to estimate the following models to extract return innovation from the futures returns: 


$$
\begin{gathered}
\operatorname{RET}_{1, \mathrm{t}}=\mathrm{c}_{0}+\mathrm{c}_{1} \operatorname{RET}_{2, \mathrm{t}}+\mathrm{u}_{\mathrm{t}} \\
\mathrm{h}_{\mathrm{t}}=\alpha_{0}+\alpha_{1} \mathrm{u}_{\mathrm{t}-1}^{2}+\alpha_{2} \mathrm{~d}_{\mathrm{t}-1} \mathrm{u}_{\mathrm{t}-1}^{2}+\alpha_{3} \mathrm{~h}_{\mathrm{t}-1} \\
\mathrm{~d}_{\mathrm{t}}= \begin{cases}1 & \mathrm{u}_{\mathrm{t}}<0(\text { bad news }) \\
0 & \mathrm{u}_{\mathrm{t}} \geq 0(\text { good news })\end{cases}
\end{gathered}
$$

where $h_{t}$ is the conditional standard deviation of the $u_{t}$ process, and $u_{t}$ captures the private information of futures traded during the post-closing session.

$$
\begin{aligned}
& \operatorname{RET}_{3, \mathrm{t}}=\mathrm{c}_{0}+\mathrm{c}_{1} \mathrm{RET}_{1, \mathrm{t}-1}+\mathrm{v}_{\mathrm{t}} \\
& \mathrm{h}_{\mathrm{t}}=\beta_{0}+\beta_{1} \mathrm{v}_{\mathrm{t}-1}^{2}+\beta_{2} \mathrm{~d}_{\mathrm{t}-1} \mathrm{v}_{\mathrm{t}-1}^{2}+\beta_{3} \mathrm{~h}_{\mathrm{t}-1} \\
& \mathrm{~d}_{\mathrm{t}}=\left\{\begin{array}{cc}
1 & \left.\mathrm{v}_{\mathrm{t}}<0 \text { (bad news }\right) \\
0 & \mathrm{v}_{\mathrm{t}} \geq 0 \text { (good news) }
\end{array}\right.
\end{aligned}
$$

where $\mathrm{v}_{\mathrm{t}}$ captures the private information of futures traded during the pre-opening session.

In the second stage, we regress the overnight spot market return on the return innovation from the futures during the extended trading hours. That is, we estimate the following T-GARCH $(1,1)$ model:

$$
\begin{gathered}
\operatorname{RET}_{300, \mathrm{t}}=\mathrm{c}_{0}+\mathrm{c}_{1} \mathrm{u}_{\mathrm{t}-1}+\mathrm{c}_{2} \mathrm{v}_{\mathrm{t}}+\varepsilon_{\mathrm{t}} \\
\mathrm{h}_{\mathrm{t}}=\gamma_{0}+\gamma_{1} \varepsilon_{\mathrm{t}-1}^{2}+\gamma_{2} \mathrm{~d}_{\mathrm{t}-1} \varepsilon_{\mathrm{t}-1}^{2}+\gamma_{3} \mathrm{~h}_{\mathrm{t}-1} \\
\mathrm{~d}_{\mathrm{t}}= \begin{cases}1 & \varepsilon_{\mathrm{t}}<0(\text { bad news }) \\
0 & \varepsilon_{\mathrm{t}} \geq 0(\text { good news })\end{cases}
\end{gathered}
$$

\section{Results}

\subsection{Descriptive Statistics}

Figure 1 depicts the CSI 300 index (spot market) return volatility and volume. We calculate return volatility using two methods: the high-low (HL) method and the end-to-end (EE) method (Parkinson, 1980). The extreme value variance estimator is superior to the traditional close-to-close variance estimator in providing an efficient estimate of return volatility. The return volatility by HL method is calculated as the following:

$$
\operatorname{VOLATILITY}_{i}=\left(\frac{1}{n} \sum_{t=1}^{n}\left[\ln \left(P_{i, t}^{h}\right)-\ln \left(P_{i, t-1}^{l}\right)\right]^{2}\right)^{0.5}
$$

where $\mathrm{P}_{\mathrm{i}, \mathrm{t}}^{\mathrm{h}}$ is CSI futures' highest price and $\mathrm{P}_{\mathrm{i}, \mathrm{t}}^{\mathrm{l}}$ is the lowest price during session $\mathrm{i}$ on day $\mathrm{t}$, and $\mathrm{n}$ is the number of observations.

The volatility by EE method is calculated as the following:

$$
\operatorname{VOLATILITY}_{i}=\left(\frac{1}{n} \sum_{t=1}^{n}\left[\ln \left(P_{i, t}^{e}\right)-\ln \left(P_{i, t-1}^{e}\right)\right]^{2}\right)^{0.5}
$$

where $P_{i, t}^{e}$ is the closing price of time t and $P_{i, t-1}^{e}$ is the closing price of time $\mathrm{t}-1$.

The volume is calculated as the following: 


$$
\operatorname{VOLUME} E_{i}=\frac{1}{n} \sum_{t=1}^{n}\left[\operatorname{VOLUME} E_{i, t}\right]
$$

Similarly, Figure 2 panels (a)-(d) portray the trading of index futures of four different contracts, IF01-IF04 ${ }^{3}$. Figure 1 and Figure 2 show that spot and futures markets have similar pattern of return volatility. Additionally, IF01-IF03 contracts share similar patterns of return volatility and volume, too. IF04 is slightly different. We then, in the following analysis, use the IF01 contract as our sample because this is the contract with the largest trading volume among the four types of contracts.

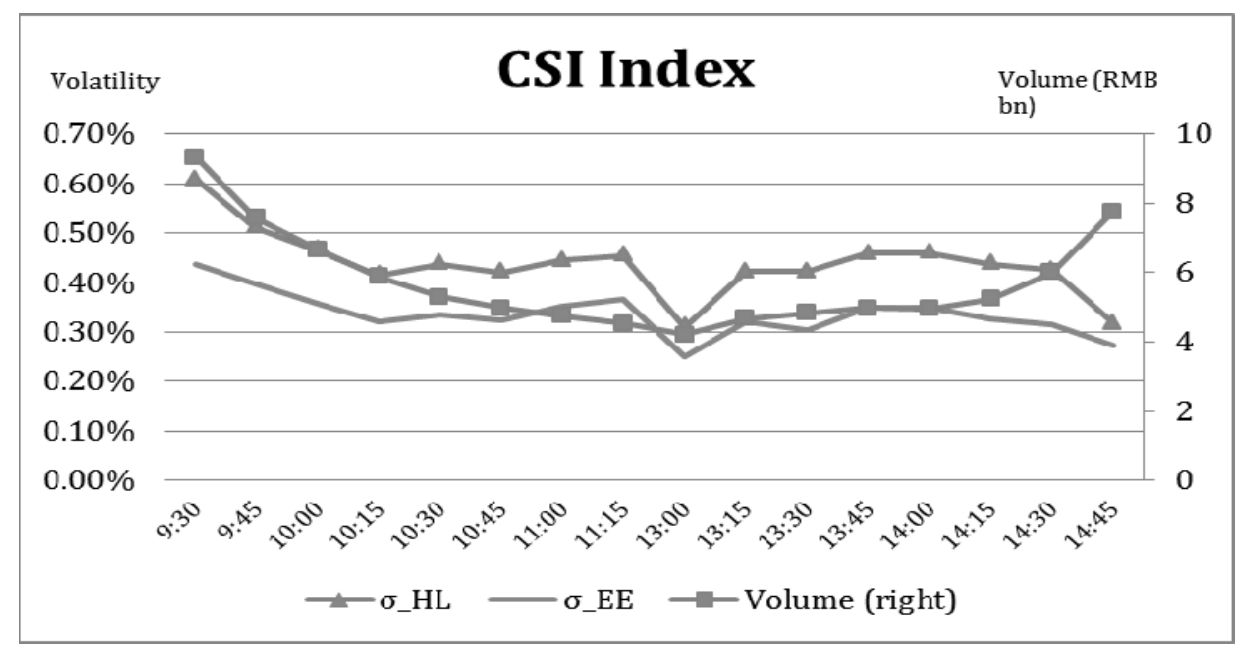

Figure 1. Price Volatility of CSI300 Index (Spot Market)

This graph presents the price volatility, calculated using the High-Low method ( $\sigma$ HL) and End-to-End method ( $\sigma$ EE) (Parkinson, 1980), as well as trading volume CSI 300 index (spot market). The volatility calculated using High-Low method is based on the following model:

$$
\operatorname{VOLATILITY}_{i}=\left(\frac{1}{n} \sum_{t=1}^{n}\left[\ln \left(P_{i, t}^{h}\right)-\ln \left(P_{i, t}^{l}\right)\right]^{2}\right)^{0.5}
$$

where $\mathrm{P}_{\mathrm{i}, \mathrm{t}}^{\mathrm{h}}$ is CSI 300 index' highest price and $\mathrm{P}_{\mathrm{i}, \mathrm{t}}^{\mathrm{l}}$ is the lowest price during session $\mathrm{i}$ on day $\mathrm{t}$, and $\mathrm{n}$ is the number of observations. The extreme value variance estimator is superior to the traditional close-to-close variance estimator in providing an efficient estimate of return volatility.

The End-to-End method is based on the following model:

$$
\operatorname{VOLATILITY}_{i}=\left(\frac{1}{n} \sum_{t=1}^{n}\left[\ln \left(P_{i, t}^{e}\right)-\ln \left(P_{i, t-1}^{e}\right)\right]^{2}\right)^{0.5}
$$

\footnotetext{
${ }^{3}$ IF01, IF02, IF03 and IF04 are four different index futures contracts with different maturity dates: these are contracts with maturity dates in the current month, next month, the last month of the closest quarter, and the last month of the next closest quarter. For example, assuming it currently is April, IF01-04 refer to contracts with maturity dates at the third Friday in April, May, June, and September, respectively. If the current month is May, then IF01-04 refer to contracts with maturity dates at the third Friday in May, June, September, and December, respectively.
} 


\section{Macrothink}

The trading volume is calculated as:

$$
\operatorname{VOLUME} E_{i}=\frac{1}{n} \sum_{t=1}^{n}\left[\operatorname{VOLUM} E_{i, t}\right]
$$

This graph presents the price volatility, calculated using the High-Low method ( $\sigma$ HL) and End-to-End method ( $\left.\sigma \_E E\right)$ (Parkinson, 1980), as well as trading volume of four different contracts of the CSI 300 index. All variables are defined in Figure 1.

(a)

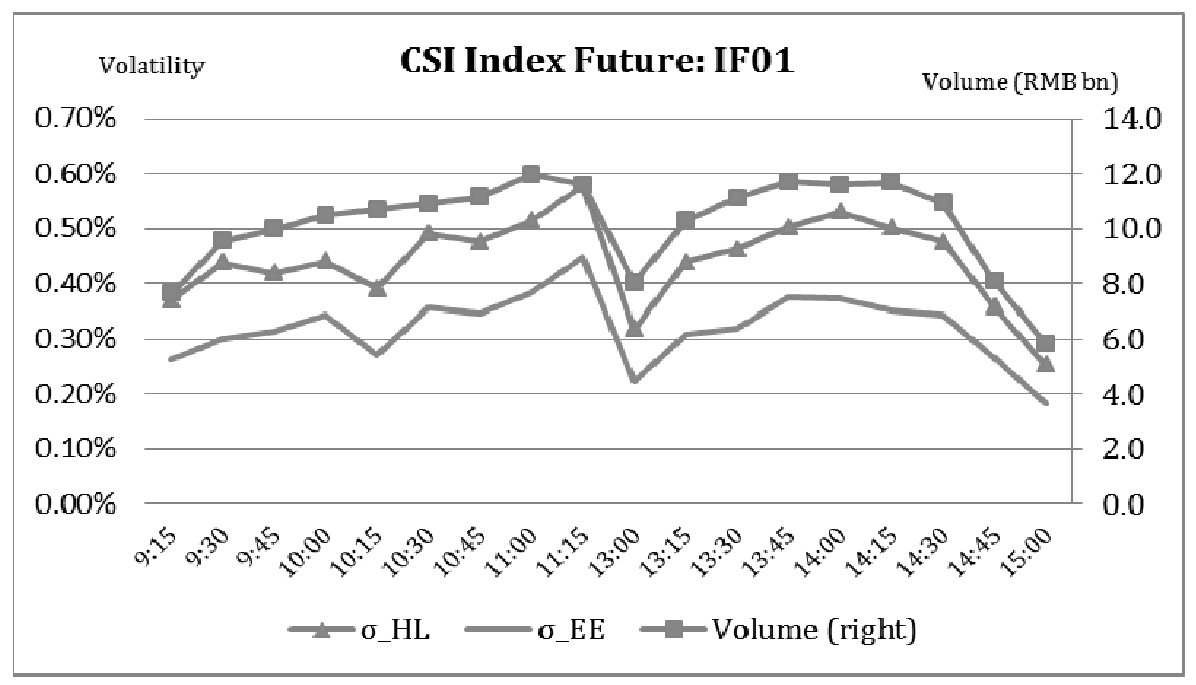

(b)

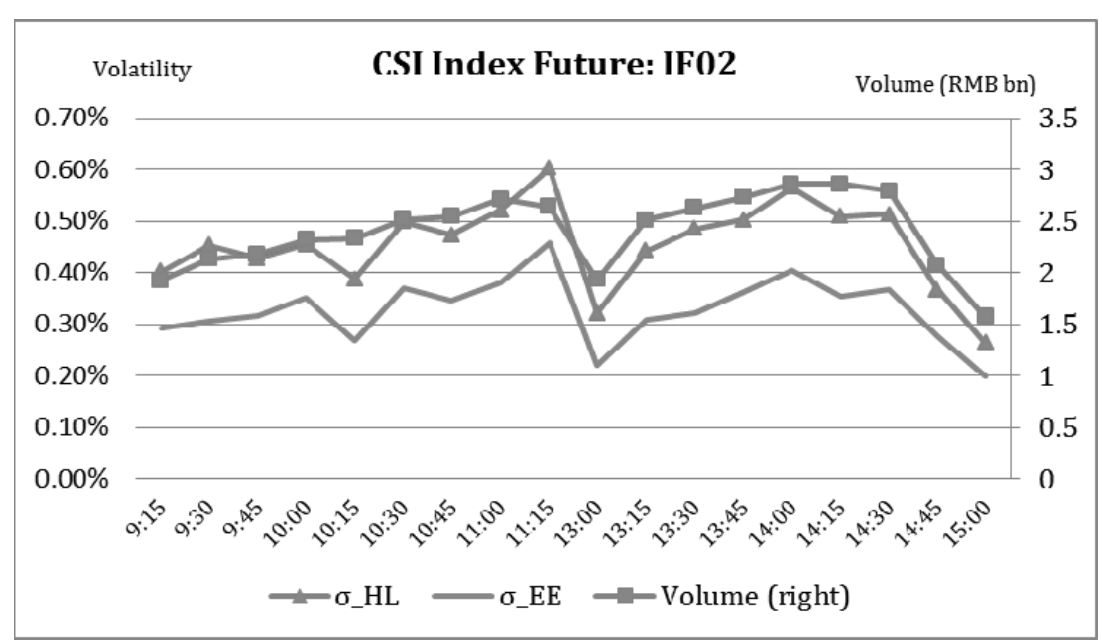


(c)

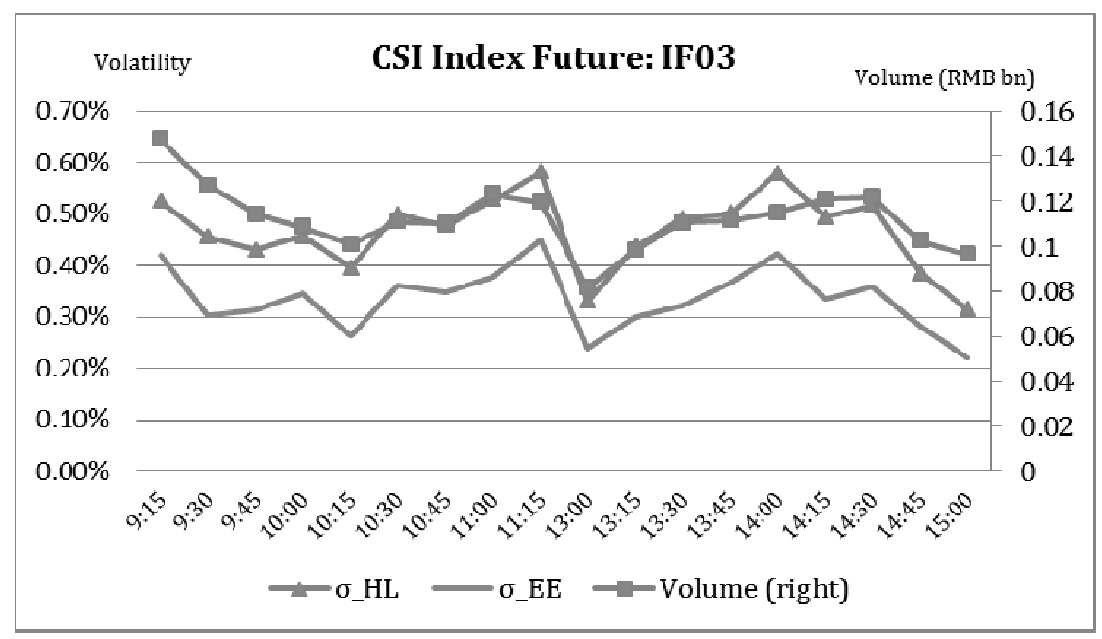

(d)

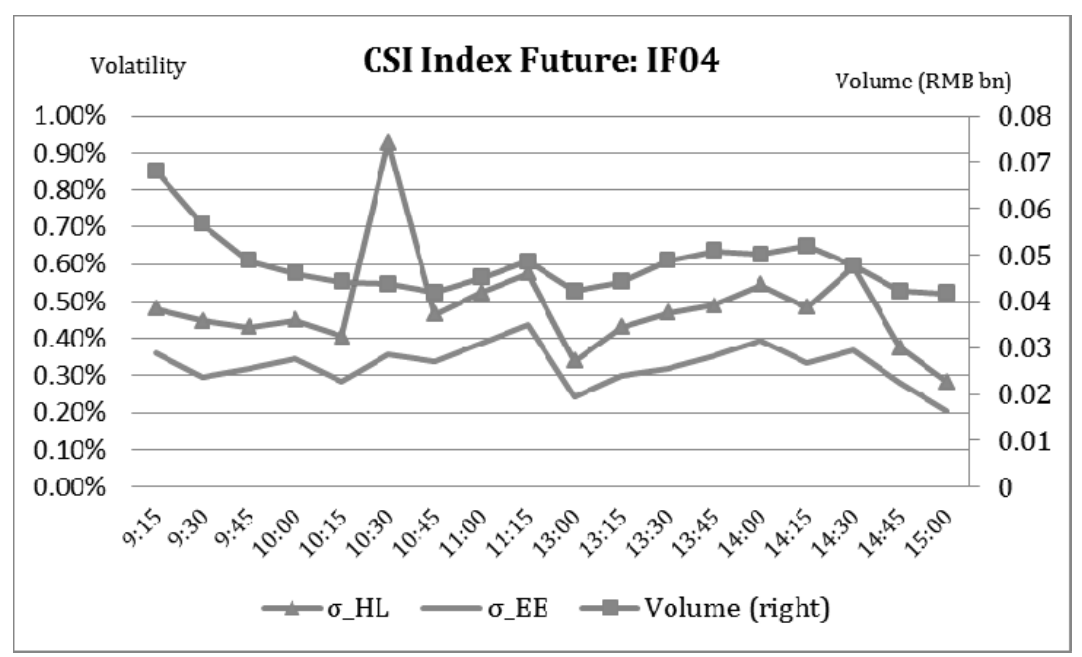

Figure 2. Price Volatility of CSI 300 Index Futures

Table 1 reports descriptive statistics of the variables. By comparing $\mathrm{RET}_{1}, \mathrm{RET}_{2}$ and $\mathrm{RET}_{3}$, we observe that $\mathrm{RET}_{2}$ is larger than returns in the other two sessions. This indicates that overnight information usually triggers more price reactions than that in the extended trading hours. Table 2 reports the Pearson correlation coefficients among variables. The overnight spot return is positively and significantly related to the overnight and the pre-opening futures return.

Table 1. Descriptive Statistics of Variables

This table presents descriptive statistics of the CSI 300 index spot market return and the returns on three trading sessions of the CSI 300 index futures when the spot market is closed. Specifically, $\mathbf{R E T}_{\mathbf{3 0 0}}$ is the total return of the CSI 300 index during the non-trading hours of 
the spot market. $\mathrm{RET}_{300}$ is calculated as the difference between the closing price of day $\mathrm{t}$ and the opening prices of day $\mathrm{t}+1$ of the CSI 300 index, divided by the closing price of the CSI 300 index of day t. $\mathbf{R E T}_{\mathbf{1}}$ is the return of stock index futures during 15:00-15:15, $\mathbf{R E T}_{\mathbf{2}}$ is the return of stock index futures during 15:15 - 9:15 (next day), and $\mathbf{R E T}_{\mathbf{3}}$ is the return of stock index futures during 9:15-9:30.

\begin{tabular}{llllll}
\hline Variable & Mean & Std.Dev & Median & Max & Min \\
\hline RET $_{300}$ & $\mathbf{0 . 0 0 1}^{* * \mathbf{a}}$ & 0.008 & -0.001 & 0.021 & -0.029 \\
$\mathrm{RET}_{1}$ & 0.000 & 0.002 & 0.000 & 0.006 & -0.007 \\
$\mathrm{RET}_{2}$ & $\mathbf{0 . 0 0 1}^{* *}$ & 0.007 & 0.001 & 0.030 & -0.026 \\
$\mathrm{RET}_{3}$ & 0.000 & 0.003 & 0.000 & 0.009 & -0.008 \\
t-tests: & & & & \\
Null & Conclusion & P-value & & & \\
Ret $_{1}=$ Ret $_{2}$ & Rejected & 0.068 & & & \\
Ret $_{2}=$ Ret $_{3}$ & Rejected & 0.062 & & & \\
Ret $_{1}=$ Ret $_{3}$ & & 0.970 & & & \\
\hline
\end{tabular}

Note: $* * * * * *$ represent statistical significance at levels of $1 \%, 5 \%$ and $10 \%$, respectively.

${ }^{\mathrm{a}} \mathrm{T}$-test is performed to examine whether the mean of the variable is significantly different from 0 .

Table 2. Correlation Table

\begin{tabular}{lllll}
\hline & $\mathrm{RET}_{300}$ & $\mathrm{RET}_{1}$ & $\mathrm{RET}_{2}$ & $\mathrm{RET}_{3}$ \\
\hline $\mathrm{RET}_{300}$ & 1 & & & \\
$\mathrm{RET}_{1}$ & 0.097 & 1 & & \\
$\mathrm{RET}_{2}$ & $\mathbf{0 . 7 2 2}^{* * *}$ & -0.091 & 1 & 1 \\
$\mathrm{RET}_{3}$ & $\mathbf{0 . 4 2 4}$ & -0.011 & 0.072 & 1 \\
\hline
\end{tabular}

\subsection{Information Captured by the Futures and Spot Markets}

To test hypothesis H1, we estimate Eq (1) using the T-GARCH model developed in Zakoian (1994), and results are presented in Table 3. The coefficients for $\mathrm{RET}_{1}, \mathrm{RET}_{2}$, and $\mathrm{RET}_{3}$ are positive and significant at the 1\% level, with a z-statistic of 9.956, 27.833 and 13.620, respectively. This indicates that information reflected in spot prices is also incorporated in futures prices. Entering $\mathrm{RET}_{1}, \mathrm{RET}_{2}$, and $\mathrm{RET}_{3}$ one by one into the regression generates similar results. 


\section{Macrothink}

Table 3. Information Captured by Futures Market and Spot Market When Spot Market Is Closed

This table presents the multiple regression results of Eq (1) using TGARCH $(1,1)$ model (Zakoian, 1994). $\mathbf{R E T}_{\mathbf{3 0 0}}$ is the total return of CSI 300 index during the non-trading hours of the spot market. That is, $\mathrm{RET}_{300}$ is calculated as the difference between the closing price of day $t$ and the opening price of day $t+1$ of the CSI 300 index, divided by the closing price of the CSI 300 index of day t. RET $\mathbf{P}_{\mathbf{1}}$ is the return of stock index futures during 15:00-15:15, $\mathbf{R E T}_{\mathbf{2}}$ is the return of stock index futures during 15:15 - 9:15 (next day), and $\mathbf{R E T} \mathbf{T}_{\mathbf{3}}$ is the return of stock index futures during 9:15-9:30.

$$
\begin{gathered}
\operatorname{RET}_{300, \mathrm{t}}=\mathrm{c}_{0}+\mathrm{c}_{1} \operatorname{RET}_{1, \mathrm{t}}+\mathrm{c}_{2} \operatorname{RET}_{2, \mathrm{t}}+\mathrm{c}_{3} \operatorname{RET}_{3, \mathrm{t}}+\epsilon_{\mathrm{t}} \\
\mathrm{h}_{\mathrm{t}}=\delta_{0}+\delta_{1} \epsilon_{\mathrm{t}-1}^{2}+\delta_{2} \mathrm{~d}_{\mathrm{t}-1} \epsilon_{\mathrm{t}-1}^{2}+\delta_{3} \mathrm{~h}_{\mathrm{t}-1} \\
\mathrm{~d}_{\mathrm{t}}= \begin{cases}1 & \epsilon_{\mathrm{t}}<0(\text { bad news }) \\
0 & \epsilon_{\mathrm{t}} \geq 0(\text { good news })\end{cases}
\end{gathered}
$$

$\epsilon_{\mathrm{t}}$ is the residual of the model.

\begin{tabular}{lllll}
\hline & $(1)$ & $(2)$ & $(3)$ & $(4)$ \\
VARIABLES & RET300 & RET300 & RET300 & RET300 \\
\hline Intercept & $-0.001^{* * *}$ & $-0.001^{* *}$ & $-0.001^{* * *}$ & $-0.001^{* *}$ \\
& $(-7.017)$ & $(-2.160)$ & $(-3.676)$ & $(-1.191)$ \\
RET1 $_{1}$ & $\mathbf{0 . 8 0 7}^{* * *}$ & $\mathbf{0 . 8 6 2}^{* * *}$ & & \\
& $(9.956)$ & $(3.304)$ & & \\
RET $_{2}$ & $\mathbf{0 . 8 6 5}^{* * *}$ & & $\mathbf{0 . 8 6 5} 5^{* * *}$ & \\
& $(27.833)$ & & $(20.643)$ & \\
$\mathrm{RET}_{3}$ & $\mathbf{1 . 0 0 5}$ & & & $\mathbf{1 . 2 4 3 ^ { * * * }}$ \\
& $(13.620)$ & & & $(9.309)$ \\
Intercept $^{* * *}$ & $0.002^{* * *}$ & $-0.009^{* * *}$ & $0.006^{* * *}$ & -0.004 \\
$\varepsilon_{\mathrm{t}-1}^{2}$ & $(4.328)$ & $(-1.960)$ & $(6.261)$ & $(-2.549)$ \\
& $0.478^{* * *}$ & 0.059 & 0.003 & 0.074 \\
$\mathrm{~d}_{\mathrm{t}-1} \varepsilon_{\mathrm{t}-1}^{2}$ & $(3.235)$ & $(1.193)$ & $(0.039)$ & $(1.317)$ \\
& $0.381^{* * *}$ & -0.008 & $0.468^{* * *}$ & -0.074 \\
$\mathrm{~h}_{\mathrm{t}-1}$ & $(2.940)$ & $(-0.457)$ & $(5.117)$ & $(-1.335)$ \\
& 0.095 & $2.139^{* * *}$ & $-0.307^{* *}$ & $1.513^{* * *}$ \\
$\mathrm{~N}$ & $(1.130)$ & $(3.293)$ & $(-2.036)$ & $(3.221)$ \\
wald chi2 & 208 & 208 & 208 & 208 \\
Log Likelihood & 882.619 & 10.915 & 426.138 & 86.657 \\
Prob $>$ Chi2 & 864.150 & 732.515 & 805.790 & 745.170 \\
\hline
\end{tabular}

Note: $* * * * * * *$ represent statistical significance at levels of $1 \%, 5 \%$ and $10 \%$, respectively. z-statistics are reported in parentheses.

\subsection{Additional Information Reflected in the Futures Market}

A T-GARCH $(1,1)$ model is used to estimate Eq. (4) and Eq. (5). Table 4 reports the 


\section{Macrothink}

first-stage, in which futures return innovation (i.e. unexpected information contained in futures returns) during extended trading hours, are extracted. Panel A presents the estimated coefficients for regression using the futures return during the post-closing session $\left(\mathrm{RET}_{1}\right)$ as the dependent variable. The coefficient for $\mathrm{RET}_{2}$ is not significant. This indicates that the information reflected in the post-closing session (15:00-15:15) does not overlap with the information captured by $\mathrm{RET}_{2}$ during the regular trading hours (from 9:30-15:00). This result is different from that in the study by Cheng et al. (2004), who found a positive relation between the returns during the post-closing session and the returns during the regular trading hours. Through the T-GARCH model, we extract unexpected components from futures returns for the post-closing session $\left(\mathrm{u}_{\mathrm{t}}\right)$.

Panel B reports the estimated coefficients for regression using the pre-opening session $\left(\mathrm{RET}_{3}\right)$ as the dependent variable. The coefficient for $\mathrm{RET}_{1, \mathrm{t}-1}$ is also not significant, indicating that the information reflected in the pre-opening session (9:15 a.m. to 9:30 a.m.) does not overlap with the information captured by RET $_{1, \mathrm{t}-1}$ during the post-closing session (15:00 p.m. to 15:15 p.m.). This result is consistent with that in the study by Cheng et al. (2004). Through the T-GARCH model, we extract unexpected components from futures returns for the post-closing session $\left(\mathrm{v}_{\mathrm{t}}\right)$.

Table 4. TGARCH $(1,1)$ Models for Extracting Information Variables

This table presents multiple regression results of Eq (1) using TGARCH $(1,1)$ model (Zakoian, 1994). $\mathbf{R E T}_{1}$ is the return of stock index futures during 15:00-15:15, $\mathbf{R E T}_{2}$ is the return of stock index futures during 15:15 - 9:15 (next day), and $\mathbf{R E T}_{3}$ is the return of stock index futures during 9:15-9:30.

Panel A. Extracting Information of the Post-Closing Session

Panel A reports the extraction of the futures return innovations of the post-closing session using the following T-GARCH(1,1) model:

$$
\begin{gathered}
\operatorname{RET}_{1, \mathrm{t}}=\mathrm{c}_{0}+\mathrm{c}_{1} \operatorname{RET}_{2, \mathrm{t}}+\mathrm{u}_{\mathrm{t}} \\
\mathrm{h}_{\mathrm{t}}=\alpha_{0}+\alpha_{1} \mathrm{u}_{\mathrm{t}-1}^{2}+\alpha_{2} \mathrm{~d}_{\mathrm{t}-1} \mathrm{u}_{\mathrm{t}-1}^{2}+\alpha_{3} \mathrm{~h}_{\mathrm{t}-1} \\
\mathrm{~d}_{\mathrm{t}}= \begin{cases}1 & \mathrm{u}_{\mathrm{t}}<0(\text { bad news }) \\
0 & \mathrm{u}_{\mathrm{t}} \geq 0(\text { good news })\end{cases}
\end{gathered}
$$

where $\mathbf{u}_{\mathbf{t}}$ is the residual of our model. 


\begin{tabular}{lcll}
\hline Variable & Coefficient & Estimate & z-stat. \\
\hline Intercept & $\mathrm{c}_{0} \times 10^{-3}$ & 0.183 & 1.319 \\
$\mathrm{RET}_{2}$ & $\mathrm{c}_{1}$ & -0.027 & -1.328 \\
& & & \\
Intercept & $\alpha_{0}$ & 0.001 & 0.822 \\
$\varepsilon_{\mathrm{t}-1}^{2}$ & $\alpha_{1}$ & -0.202 & $-2.231^{* *}$ \\
$\mathrm{~d}_{\mathrm{t}-1} \varepsilon_{\mathrm{t}-1}^{2}$ & $\alpha_{2}$ & 0.032 & 0.347 \\
$\mathrm{~h}_{\mathrm{t}-1}$ & $\alpha_{3}$ & 0.762 & $1.739^{*}$ \\
& & & \\
\hline $\mathrm{N}$ & & 208 & \\
Log-Likelihood & & 1.763 & \\
Wald chi2 & & 1019.885 & \\
Prob $>$ chi2 & & 0.184 & \\
\hline
\end{tabular}

Table 4 (Cont'd)

Panel B. Extracting Information of the Pre-Opening Session

Panel B reports the extraction of the futures return innovations of the pre-opening session using the following T-GARCH $(1,1)$ model:

$$
\begin{gathered}
\operatorname{RET}_{3, \mathrm{t}}=\mathrm{c}_{0}+\mathrm{c}_{1} \operatorname{RET}_{1, \mathrm{t}-1}+\mathrm{v}_{\mathrm{t}} \\
\mathrm{h}_{\mathrm{t}}=\beta_{0}+\beta_{1} \mathrm{v}_{\mathrm{t}-1}^{2}+\beta_{2} \mathrm{~d}_{\mathrm{t}-1} \mathrm{v}_{\mathrm{t}-1}^{2}+\beta_{3} \mathrm{~h}_{\mathrm{t}-1} \\
\mathrm{~d}_{\mathrm{t}}= \begin{cases}1 & \mathrm{v}_{\mathrm{t}}<0(\text { bad news }) \\
0 & \mathrm{v}_{\mathrm{t}} \geq 0(\text { good news })\end{cases}
\end{gathered}
$$

where $\mathbf{v}_{\mathbf{t}}$ is the residual of our model.

\begin{tabular}{lcll}
\hline & & & \\
variable & Coefficient & Estimate & z-stat. \\
\hline intercept & $\mathrm{c}_{0} \times 10^{-3}$ & -0.686 & -0.274 \\
$\mathrm{RET}_{1, \mathrm{t}-1}$ & $\mathrm{c}_{1}$ & -0.155 & -1.427 \\
& & & -0.314 \\
intercept & $\beta_{0} \times 10^{-3}$ & -0.457 & $1.998^{* *}$ \\
$\varepsilon_{\mathrm{t}-1}^{2}$ & $\beta_{1}$ & 0.311 & $-1.903^{*}$ \\
$\mathrm{~d}_{\mathrm{t}-1} \varepsilon_{\mathrm{t}-1}^{2}$ & $\beta_{2}$ & -0.331 & $1.907^{*}$ \\
$\mathrm{~h}_{\mathrm{t}-1}$ & $\beta_{3}$ & 1.154 & \\
& & & \\
$\mathrm{~N}$ & & 162 & \\
Log-Likelihood & & 2.037 & \\
Wald chi2 & & 747.239 & \\
Prob $>$ chi2 & & 0.153 & \\
\hline
\end{tabular}

Note: $* * * * *, *$ represent statistical significance at levels of $1 \%, 5 \%$ and $10 \%$, respectively.

Table 5 presents the second-stage results, in which overnight spot market returns are explained by the innovations of the futures market returns. The coefficient of $\mathrm{u}_{\mathrm{t}-1}$ is negative 
and significant at the level of $10 \%$, suggesting that post-closing futures innovations are weakly negatively correlated with overnight spot returns. The coefficient of $\mathrm{v}_{\mathrm{t}}$ is positive and significant at the level of $1 \%$, with a $z$-statistic of 5.993. This indicates that pre-opening futures unexpected information has a positive impact on spot returns, consistent with the findings in Hiraki et al. (1995) and Cheng et al. (2004).

Table 5. TGARCH $(1,1)$ Model for Overnight Spot Returns

$\mathbf{R E T}_{\mathbf{3 0 0}}$ represents the overnight spot return; $\mathbf{u}_{\mathbf{t}-1}$ is the lagged futures return innovation during the post-closing session; $\mathbf{v}_{\mathbf{t}}$ is the futures return innovation during the pre-opening session; $\boldsymbol{\varepsilon}_{\mathbf{t}}$ is the residual of our model.

$$
\begin{gathered}
\operatorname{RET}_{300, \mathrm{t}}=\mathrm{c}_{0}+\mathrm{c}_{1} \mathrm{u}_{\mathrm{t}-1}+\mathrm{c}_{2} \mathrm{v}_{\mathrm{t}}+\varepsilon_{\mathrm{t}} \\
\mathrm{h}_{\mathrm{t}}=\gamma_{0}+\gamma_{1} \varepsilon_{\mathrm{t}-1}^{2}+\gamma_{2} \mathrm{~d}_{\mathrm{t}-1} \varepsilon_{\mathrm{t}-1}^{2}+\gamma_{3} \mathrm{~h}_{\mathrm{t}-1} \\
\mathrm{~d}_{\mathrm{t}}= \begin{cases}1 & \varepsilon_{\mathrm{t}}<0(\text { bad news }) \\
0 & \varepsilon_{\mathrm{t}} \geq 0(\text { good news })\end{cases}
\end{gathered}
$$

\begin{tabular}{lcll}
\hline variable & Coefficient & Estimate & z-stat. \\
\hline intercept & $\mathrm{c}_{0}$ & $-0.002^{* * *}$ & -3.384 \\
$\mathrm{u}_{\mathrm{t}-1}$ & $\mathrm{c}_{1}$ & $\mathbf{- 0 . 5 5 8}^{*}$ & -1.845 \\
$\mathrm{v}_{\mathrm{t}}$ & $\mathrm{c}_{2}$ & $\mathbf{1 . 1 0 8 ^ { * * * }}$ & 5.993 \\
intercept & $\gamma_{0}$ & 0.002 & 0.845 \\
$\varepsilon_{\mathrm{t}-1}^{2}$ & $\gamma_{1}$ & 0.265 & 1.623 \\
$\mathrm{~d}_{\mathrm{t}-1} \varepsilon_{\mathrm{t}-1}^{2}$ & $\gamma_{2}$ & $-0.390^{* * *}$ & -2.941 \\
$\mathrm{~h}_{\mathrm{t}-1}$ & $\gamma_{3}$ & $0.719^{* *}$ & 1.986 \\
\hline Observations & & 162 & \\
wald chi2 & & 36.642 & \\
Log Likelihood & & 590.724 & \\
Prob $>$ Chi2 & & 0.000 & \\
\hline
\end{tabular}

Note: $* * *,{ }^{* *},{ }^{*}$ represent statistical significance at levels of $1 \%, 5 \%$ and $10 \%$, respectively.

\subsection{Overnight Information from the U.S. Market Reflected in Futures}

To test hypothesis $\mathrm{H} 2$, we investigate the extent to which overnight U.S. market information is incorporated into the CSI 300 index futures market. Empirically, we use two types of news from the U.S. market to capture the high- versus low- news day of trading in the U.S. market. We define days in which price volatility is high (i.e., daily price volatility ranks in the top $33 \%$ ) in the U.S. market, as well as days when the Federal Reserve released interest rate news, as high-news days. We define days otherwise (i.e., daily price volatility ranks in the bottom $33 \%$, and days without interest rate news) as low-news days.

Panel A of Table 6 reports the mean and median of price change, return and trading volume of index futures during the pre-opening sessions (i.e., 9:15-9:30) in both high- and low- news days, where news is defined by price volatility in the daytime trading of the U.S. market. It 
shows that during high-news days, price changes and returns during the pre-opening sessions are not significantly different from those in the low-news days, while the trading volumes are significantly different. Panel B reports the mean and median of price change, return and trading volume of index futures during the pre-opening sessions in both high- and low- news days, where news is defined by the U.S. Federal Reserve interest rate news. Panel B shows that the price changes in the high- versus low-news days are significantly different for the pre-opening trading of index futures. Combined, the price discovery process of the index futures before the spot market opens appear to be effective in reflecting overnight U.S. market news.

Table 6. Incorporation of U.S. Market Overnight Information for the Futures Market Panel A. High/Low- News Days Defined by U.S. Market Trading

\begin{tabular}{llllllll}
\hline $\mathrm{R}_{\mathrm{s}}$ & Obs. & Mean & & \multicolumn{3}{c}{ Median } \\
& & $\begin{array}{l}\text { Price } \\
\text { Change }\end{array}$ & Return & $\begin{array}{l}\text { Volume } \\
\text { (Billion) }\end{array}$ & $\begin{array}{l}\text { Price } \\
\text { Change }\end{array}$ & Return & $\begin{array}{l}\text { Volume } \\
\text { (Billion) }\end{array}$ \\
\hline Lowest 33\% & 45 & $0.34 \%$ & $0.22 \%$ & 6.707 & $0.24 \%$ & $0.18 \%$ & 6.725 \\
Highest 33\% & 45 & $0.30 \%$ & $0.18 \%$ & 9.029 & $0.25 \%$ & $0.12 \%$ & 8.646 \\
High-Low & & $0.04 \%$ & $0.03 \%$ & $-2.322^{* * *}$ & $-0.01 \%$ & $0.06 \%$ & $-1.921^{* * *}$ \\
$\mathrm{P}$ & & 0.41 & 0.76 & 0.01 & 0.36 & 0.2 & 0.01 \\
\hline
\end{tabular}

Note: $R_{s}$ is the absolute value of the S\&P500's return at last night. We divided the trading day in the sample into three groups of high, medium and low in accordance with price fluctuations of U.S. stocks in the last night. The trading day with the highest price change of U.S. stocks was used as the trading day with the most overnight information. On the contrary, the trading day with the lowest price change of U.S. stocks was used as the trading day with the least overnight information.

$* * *, * * *$ represent statistical significance at levels of $1 \%, 5 \%$ and $10 \%$, respectively.

Panel B. High/Low- News Days Defined by U.S. Fed Interest Rate News Release

\begin{tabular}{|c|c|c|c|c|c|c|c|}
\hline \multirow[t]{2}{*}{ Information } & \multirow[t]{2}{*}{ Obs. } & \multicolumn{3}{|l|}{ Mean } & \multicolumn{3}{|l|}{ Median } \\
\hline & & $\begin{array}{l}\text { Price } \\
\text { Change }\end{array}$ & Return & $\begin{array}{l}\text { Volume } \\
\text { (billion) }\end{array}$ & $\begin{array}{l}\text { Price } \\
\text { Change }\end{array}$ & Return & $\begin{array}{l}\text { Volume } \\
\text { (billion) }\end{array}$ \\
\hline $\mathrm{N}(1)$ & 199 & $0.30 \%$ & $0.19 \%$ & 7.544 & $0.26 \%$ & $0.14 \%$ & 7.489 \\
\hline $\mathrm{N}(2)$ & 9 & $0.46 \%$ & $0.26 \%$ & 9.206 & $0.44 \%$ & $0.20 \%$ & 8.216 \\
\hline$N(1)-N(2)$ & & $-0.16 \%{ }^{* * *}$ & $-0.07 \%$ & -1.662 & $-0.18 \%{ }^{* * *}$ & $-0.05 \%$ & -0.727 \\
\hline $\mathrm{p}$ & & 0.02 & 0.48 & 0.41 & 0.02 & 0.4 & 0.35 \\
\hline
\end{tabular}

Note: We collected nine samples of monetary policy adjustment events from the 208 trading days and used the nine trading days with overnight monetary policy adjustments as the trading day with important overnight information. We compared the trading behavior during the first 15 minutes of the opening of the stock futures market in these nine trading days (N (2)) with the remaining 199 trading days (N (1)).

$* * *, * *,{ }^{*}$ represent statistical significance at levels of $1 \%, 5 \%$ and $10 \%$, respectively. 


\section{Conclusions}

In this paper, we study the information role of the newly launched futures market in China. In particular, we examine information incorporations of the futures market during the extended trading sessions to the underlying spot market. Our findings are three-folded. First, the spot market is the main information source to the futures market, and private information incorporation of the futures market after spot market closes becomes significantly weaker. This indicates a weak informational efficiency of the futures market. Second, using a T-GARCH(1,1) model, we test whether the return innovations in the futures market are correlated with the spot market, and we confirmed a positive relation between returns from the two market. Third, we test whether futures market incorporate additional news from the overseas market (i.e., the U.S. market) and we confirm a positive answer to this research question. Overall, our results show that the futures market in such a strong politically controlled economy is informationally functional, but only to a weak extent.

Our paper adds to the current discussion of information content of newly incepted markets such as Japan, Korea and Hong Kong. Grossman (1977) point out that future market can facilitate information transfer from informed investors to uninformed investors, and our results indicate that futures market in China fulfills this information transmission role.

The implications of our results are not only theoretical but also practical. For example, in China there are limited invest instruments to form complicated investment strategies for institutional investors, but the futures market, if informationally efficient, adds to the possible instruments for institutional investors. Especially, the extended trading hours provided additional investment opportunities.

\section{Acknowledgement}

The authors would like to thank Liming Zhao, Jinsong Tan, and the research team at the China Financial Futures Exchange (FFEX) for helpful comments and suggestions. This study, originally written in Chinese, won the best paper award in the research competition held by the FFEX in 2011. Karen Jingrong Lin would like to thank Business School at the Sun Yat-sen University for the financial assistance at the time this paper was written.

\section{References}

Antoniou, A., \& Holmes, P. (1995). Futures trading, information and spot price volatility: evidence for the FTSE-100 stock index futures contract using GARCH. Journal of Banking \& Finance, 19(1), 117-129. http://dx.doi.org/10.1016/0378-4266(94)00059-C

Bigman, D., Goldfarb, D., \& Schechtman, E. (1983). Futures Market Efficiency and the Time Content of the Information Sets. The Journal of Futures Markets (pre-1986), 3(3), 321-321. http://dx.doi.org/10.1002/fut.3990030307

Chang, E. C., Cheng, J. W., \& Pinegar, J. M. (1999). Does futures trading increase stock market volatility? The case of the Nikkei stock index futures markets. Journal of Banking \& Finance, 23(5), 727-753. http://dx.doi.org/10.1016/S0378-4266(98)00069-7

Cheng, L. T. W., Jiang, L., \& Ng, R. W. Y. (2004). Information content of extended trading 
for index futures. Journal of Futures Markets, 24(9), 861-886. http://dx.doi.org/10.1002/fut.20110

Chiang, M.-H., \& Wang, C.-Y. (2002). The impact of futures trading on spot index volatility: evidence for Taiwan index futures. Applied Economics Letters, 9(6), 381-385. http://dx.doi.org/10.1080/13504850110068837

Chong, T. T.-L., Lam, T.-H., \& Yan, I. K.-M. (2012). Is the Chinese stock market really inefficient? [Article]. China Economic Review (1043951X), 23(1), 122-137. http://dx.doi.org/10.1016/j.chieco.2011.08.003

Engle, R. F., \& Ng, V. K. (1993). Measuring and Testing the Impact of News on Volatility. The Journal of $\quad$ Finance, $48(5), \quad 1749-1778$. http://dx.doi.org/10.1111/j.1540-6261.1993.tb05127.x

Foster, F. D., \& Viswanathan, S. (1994). Strategic Trading with Asymmetrically Informed Traders and Long-Lived Information. Journal of Financial and Quantitative Analysis, 29(04), 499-518. http://dx.doi.org/10.2307/2331107

Grossman, S. J. (1977). The existence of futures markets, noisy rational expectations and informational externalities. The Review of Economic Studies, 44(3), 431-449. http://dx.doi.org/10.2307/2296900

Gul, F. A., Kim, J.-b., \& Qiu, A. A. (2010). Ownership concentration, foreign shareholding, audit quality, and stock price synchronicity: Evidence from China Journal of Financial Economics, 95(3), 425-442. http://dx.doi.org/10.1016/j.jfineco.2009.11.005

Hiraki, T., Maberly, E. D., \& Takezawa, N. (1995). The information content of end-of-the-day index futures returns: International evidence from the Osaka Nikkei 225 futures contract. $\begin{array}{llll}\text { Journal of Banking \& } \quad \text { Finance, } & 19(5), \quad \text { 921-936. }\end{array}$ http://dx.doi.org/10.1016/0378-4266(94)00064-A

King, M., \& Wadhwani, S. (1990). Transmission of volatility between stock markets. Review of Financial Studies, 3(1), 5-33. http://dx.doi.org/10.1093/rfs/3.1.5

Kyle, A. S. (1985). Continuous Auctions and Insider Trading. Econometrica, 53(6), 1315-1335. http://dx.doi.org/10.2307/1913210

Lin, W.-L., Engle, R., \& Ito, T. (1994). Do bulls and bears move across borders? International transmission of stock returns and volatility. Review of Financial Studies, 7(3), 507-538. http://dx.doi.org/10.1093/rfs/7.3.507

Min, J. H., \& Najand, M. (1999). A further investigation of the lead-lag relationship between the spot market and stock index futures: Early evidence from Korea. Journal of Futures Markets, $19(2)$,

217-232. http://dx.doi.org/10.1002/(SICI)1096-9934(199904)19:2<217::AID-FUT5>3.0.CO;2-8

Morck, R., Yeung, B., \& Yu, W. (2000). The information content of stock markets: Why do emerging markets have synchronous stock price movements? Journal of Financial 
Economics, 58(1,2), 215-260.

Parkinson, M. (1980). The Extreme Value Method for Estimating the Variance of the Rate of Return. The Journal of Business, 53(1), 61-65. doi: 10.2307/2352357

Zakoian, J.-M. (1994). Threshold heteroskedastic models. Journal of Economic Dynamics and Control, 18(5), 931-955. http://dx.doi.org/10.1016/0165-1889(94)90039-6 